\title{
Portentous pinball
}

\author{
Christian Fellowes MBBS, Caroline Daly MRCP, Sonya V Babu-Narayan MRCP, \\ Jonathan Lyne MRCP, Julian Collinson MD
}

\section{Fellowes, C Daly, SV Babu-Narayan, J Lyne, J Collinson. Portentous pinball. Can J Cardiol 2008;24(2):e3-e5.}

\begin{abstract}
A 76-year-old woman presented with a six-day history of pleuritic pain, dyspnea and a swollen, tender left calf. She was dyspneic, tachypneic and tachycardic (heart rate 109 beats/min), with decreased oxygen saturation (83\%) and a partial pressure of oxygen of $9 \mathrm{kPa}$. Her blood pressure was $119 / 79 \mathrm{mmHg}$, and she had elevated jugular venous pressure $(11 \mathrm{mmHg})$. A computed tomographic pulmonary angiogram revealed extensive bilateral pulmonary artery thrombi and an ultrasound confirmed a lower limb thrombus. Echocardiography demonstrated a dilated right ventricle with pulmonary artery hypertension $(75 \mathrm{mmHg}$ ) and a free-floating thrombus of $1.5 \mathrm{~cm} \times 4 \mathrm{~cm}$, which ricocheted across the right ventricular outflow tract from the tricuspid to the pulmonary valve. The left ventricle was underfilled and hyperdynamic. Following thrombolysis, the patient's clinical status improved. Echocardiography revealed improved biventricular function, no residual right ventricular thrombus, and pulmonary artery pressure normalization. The present case demonstrates the usefulness of echocardiography in submassive pulmonary embolus risk stratification and management.
\end{abstract}

Key Words: Echocardiography; Embolism; Pulmonary hypertension; Thrombolysis; Thrombosis

\section{CASE PRESENTATION}

A 76-year-old woman presented to hospital with a six-day history of right-sided pleuritic pain, progressive dyspnea and a swollen, tender left calf. She had a background history of breathlessness for the preceding three weeks. She had a smoking history in excess of 50 pack-years and a pulmonary embolus one year before with no obvious precipitating factors; she was treated with warfarin and made a complete recovery.

On respiratory examination, the patient was dyspneic and tachypneic (respiratory rate of 25 breaths/min), desaturating on room air to $83 \%$, with partial pressure of oxygen of $9 \mathrm{kPa}$. She was tachycardic, at 109 beats/min, and her jugular venous pressure was increased to $11 \mathrm{mmHg}$ at a $45^{\circ}$ incline to horizontal. Her systemic blood pressure was $119 / 79 \mathrm{mmHg}$, appearing sufficient to maintain tissue perfusion.

A subsequent electrocardiogram revealed sinus tachycardia with right-axis deviation and right-sided $\mathrm{T}$ wave inversion, consistent with a right ventricular (RV) strain pattern. Chest radiographs demonstrated a suspicious, peripheral spiculated lesion in the left lower zone. Computed tomographic (CT) pulmonary angiography (CTPA) revealed extensive bilateral pulmonary artery thrombi, and Doppler ultrasound confirmed deep vein thrombosis focus in the left common and superficial femoral veins, extending to the popliteal trifurcation. On echocardiography (Figure 1 and video), a free-floating thrombus of $1.5 \mathrm{~cm} \times 4 \mathrm{~cm}$ appeared to ricochet across the RV outflow tract from the tricuspid to the pulmonary valve. This was associated with a dilated and hypokinetic RV free wall, significant tricuspid regurgitation (estimated pulmonary artery systolic pressure of $75 \mathrm{mmHg}$ ) and a dilated inferior vena cava. Concomitantly, the left ventricle was underfilled and hyperdynamic.

\section{Menaçant thrombus baladeur}

Une femme de 76 ans a consulté parce qu'elle éprouvait depuis six jours des douleurs pleurétiques et de la dyspnée, accompagnées d'enflure et de douleur au mollet gauche. À l'examen, elle était dyspnéique, tachypnéique et tachycarde (fréquence cardiaque 109 battements/minute). Sa saturation en oxygène était diminuée ( $83 \%)$ et sa pression partielle d'oxygène était à $9 \mathrm{kPa}$. Sa tension artérielle était à 119/79 mm Hg et elle présentait une pression veineuse jugulaire élevée $(11 \mathrm{~mm} \mathrm{Hg})$. Une angiographie pulmonaire a révélé la présence de nombreux thrombi artériels pulmonaires bilatéraux et l'échographie a confirmé la présence d'un thrombus au membre inférieur. L'échocardiographie a révélé une dilatation du ventricule droit avec hypertension de l'artère pulmonaire $(75 \mathrm{~mm} \mathrm{Hg})$ et la présence d'un thrombus libre de $1,5 \mathrm{~cm}$ sur $4 \mathrm{~cm}$ qui faisait des ricochets dans la chambre de chasse du ventricule droit, entre la valvule tricuspide et la valvule pulmonaire. Le ventricule gauche était non rempli et hyperdynamique. Après thrombolyse, l'état clinique de la patiente s'est amélioré, l'échocardiographie a révélé une amélioration du fonctionnement des deux ventricules, aucun thrombus ventriculaire droit résiduel et une normalisation de la pression de l'artère pulmonaire. Le présent cas démontre l'utilité de l'échocardiographie dans la stratification du risque et la prise en charge de l'embolie pulmonaire submassive.

In light of these findings and negative head CT for brain metastases, alteplase-mediated thrombolysis was administered, resulting in a good response. Post-thrombolysis, her clinical parameters improved over the following $24 \mathrm{~h}$, such that her respiratory rate decreased to 16 breaths/min, her oxygen requirements decreased concurrently and cardiovascularly, her systolic blood pressure improved to $136 / 90 \mathrm{mmHg}$, with her heart rate remaining at approximately 100 beats/min. Repeat echocardiography revealed improved RV wall motion, left ventricular (LV) filling, reduced pulmonary artery systolic pressure of $45 \mathrm{mmHg}$ and absence of an RV thrombus.

Her recurrent presentation was thought to be due to a lung malignancy; however, before a definitive elucidation of her apparent prothrombotic diathesis, the patient succumbed to nosocomial bronchopneumonia and died.

\section{DISCUSSION}

The treatment of pulmonary emboli is dependent on the severity of presentation, and generally, three distinct 'clinical entities' are described. These include massive (patients who present with hemodynamic compromise), submassive (those with no compromise but evidence of RV dysfunction) and patients with neither of these features (1).

The severity of presentation is determined by the hemodynamic response to the degree of vessel obstruction (dependent on embolus size), release of pulmonary artery vasoconstrictors, and hypoxia increasing pulmonary arterial resistance. The degree of decompensation is determined by the underlying cardiorespiratory status of the patient and compensatory neurohormonal mechanisms (2).

Multiple investigations for the diagnosis and risk stratification of pulmonary emboli exist, ranging from blood tests such as D-dimer, and 


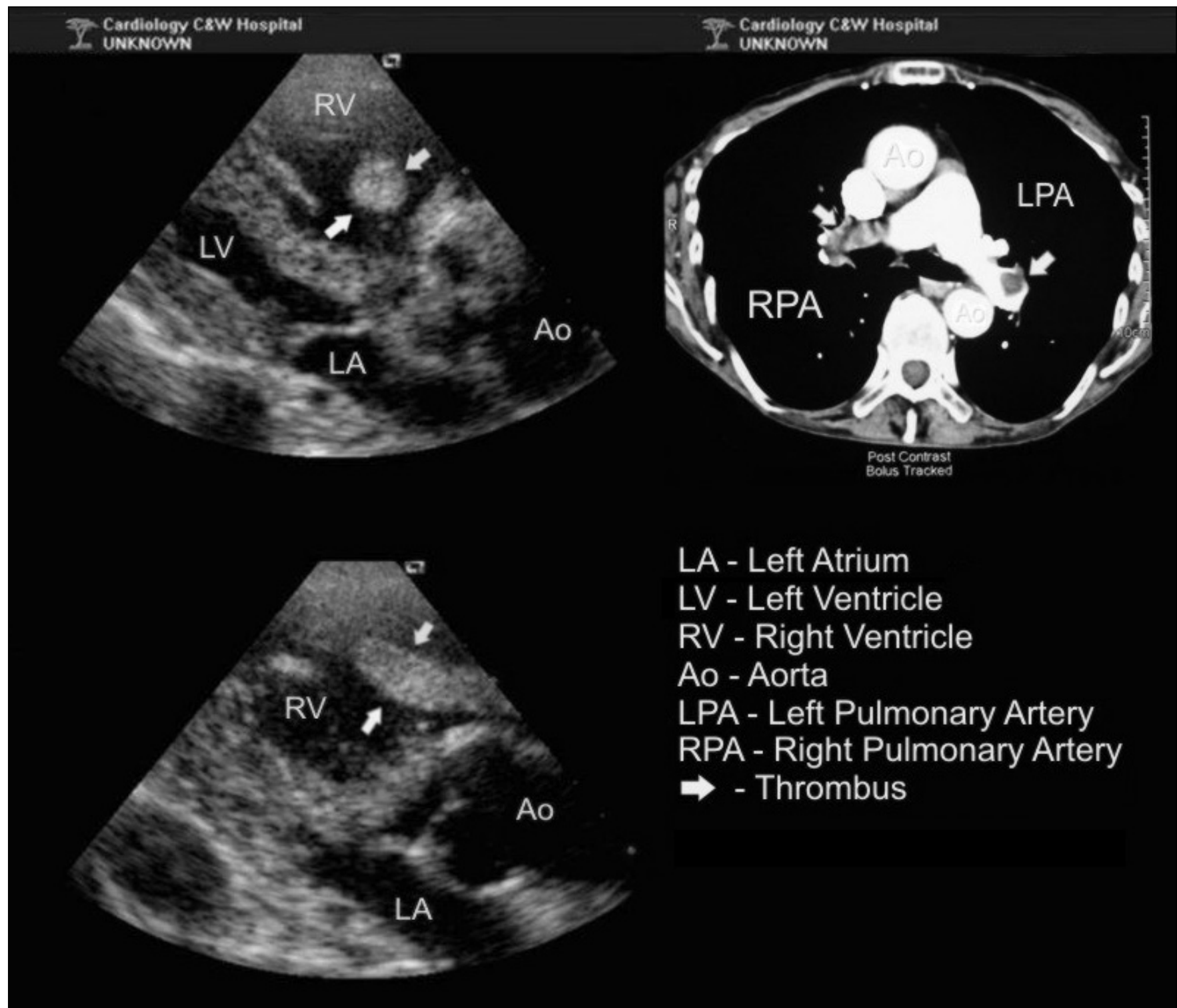

Figure 1) Computed tomography and transthoracic echocardiography images of the pulmonary embolism and right ventricular thrombus (click here to view a movie clip of the echocardiographic image)

imaging modalities such as chest radiographs, electrocardiograms and CTPA to visualize either the thrombus directly or to look for resultant effects of arterial occlusion.

CTPA is the present diagnostic modality of choice (2); however, it cannot provide absolute evidence of a patient's functional status, and as such, other modalities are required to elucidate this and subsequently risk-stratify patients.

Risk stratification is a critical component of pulmonary embolism management and focuses on determining RV strain. This is accomplished either by measuring levels of the markers B-type natriuretic peptide (BNP) and troponin (BNP is elevated because of increases in ventricular shear strain and troponin is elevated because of microinfarction due to high RV pressure loads), or by transthoracic echocardiography - this is the imaging test of choice for risk stratification, and patients with elevated troponin or BNP should proceed to echocardiography.

Evidence to look for includes RV hypokinesis, dilation and evidence of pulmonary artery hypertension (paradoxical movement of the interventricular septum into the LV, high tricuspid regurgitation velocities and dilated inferior vena cava). Of note, McConnell's sign is specific for pulmonary embolism and consists of RV dysfunction with severe free wall hypokinesia, with sparing of the apex. RV dysfunction is a useful independent predictor of early mortality (3).

The British Thoracic Society guidelines and other authorities recommend thrombolysis for hemodynamically collapsed patients; early intervention is more beneficial (4), although the extent of the benefit remains uncertain. However, the role of thrombolysis in submassive pulmonary emboli still remains to be determined. A recent study demonstrated no survival advantage in thrombolysis and heparin versus heparin alone, but did find a decreased need for emergency intervention (5). In addition, thrombolysis was twice as likely to induce a major hemorrhage.

Furthermore, transthoracic echocardiography appears to be more sensitive than other readily available imaging modalities in determining the presence of RV thrombi.

Our case was one of submassive pulmonary embolism, and thrombolysis was performed because a mobile RV thrombus was identified. Studies have shown a survival advantage in patients who are thrombolyzed (6), such as the one described in the present report.

The present case demonstrates the key role for transthoracic echocardiography in guiding decisions for thrombolysis in patients with a submassive pulmonary embolus. 


\section{REFERENCES}

1. Piazza G, Goldhaber SZ. Acute pulmonary embolism: Part II: Treatment and prophylaxis. Circulation 2006;114:e42-7.

2. Goldhaber SZ, Elliott CG. Acute pulmonary embolism: Part I: Epidemiology, pathophysiology, and diagnosis. Circulation 2003;108:2726-9.

3. Kucher N, Rossi E, De Rosa M, Goldhaber SZ. Prognostic role of echocardiography among patients with acute pulmonary embolism and a systolic arterial pressure of $90 \mathrm{~mm} \mathrm{Hg}$ or higher. Arch Intern Med 2005;165:1777-81.
4. Daniels LB, Parker JA, Patel SR, Grodstein F, Goldhaber SZ. Relation of duration of symptoms with response to thrombolytic therapy in pulmonary embolism. Am J Cardiol 1997;80:184-8.

5. Konstantinides S, Geibel A, Heusel G, Heinrich F, Kasper W; Management Strategies and Prognosis of Pulmonary Embolism-3 Trial Investigators. Heparin plus alteplase compared with heparin alone in patients with submassive pulmonary embolism. N Engl J Med 2002;347:1143-50.

6. Rose PS, Punjabi NM, Pearse DB. Treatment of right heart thromboemboli. Chest 2002;121:806-14. 